\title{
Development of ethnic tourism in poverty and drug deduction (the case study of Chiangrai Province, Thailand)
}

\author{
Bussaba Sitikarn ${ }^{1, *}$ \\ ${ }^{1}$ School of Management, Mae Fah Luang University, Chiang Rai, Thailand
}

\begin{abstract}
Despite significant economic growth in Thailand, in northern Thailand in particular, a growing number of indigenous communities have been turning to tourism as an alternative to expanding their commercial agriculture. However, in recent years, tourism resources have begun to deteriorate both culturally and environmentally in addition to problem of poverty. Thus, a growing gap between rich and poor, inadequate attention to the special needs of ethnic minorities, gender inequities and lack of access to basic health and education are significant problems. This paper presents the ethnic minorities' context and their demands on tourism development as well as the key players' roles and interests effecting on ethnic tourism promotion. The paper concluded with key issues for an achievement of creative ethnic tourism promotion in Chiang Rai Province.
\end{abstract}

\section{Introduction}

Ethnic tourism is the travelling motivated by search for the first hand and authentic experiences on other cultures that often involve with locals' performances, presentations and attractions. This kind of tourism provides tourist opportunities to have close contact with indigenous communities and its members [1].

Thus, tourists have gained knowledge, experience and practice of other local's cultures, including culture, heritage, anthropology, tribal, village and locals way of life. For example, the Karen community in the Inthanon National park in Chiang Mai province and Akha village in Chiang Rai province in Thailand.

Recently, in the Greater Mekong Sub region (GMS), ethnic tourism has been perceived by tourism stakeholders as an essential tool for sustainable tourism promotion as it can be utilized as a tool for the preservation and conservation of natural resources, culture and heritage in addition to poverty alleviation, Thailand is no exception. Ethnic tourism evidently became a focal interest among tourism stakeholders.

However, there are some studies identified the impacts of ethnic tourism on locals' socio-culture [2], culture deterioration, modification and commercialization [3,4]. To prevent those negative impacts, the case remains to be made.

Chiang Rai province is located at the most northern point of Thailand, bordered with the Republic of the Union of Myanmar and Laos. Chiang Rai is a world famous cultural

* Corresponding author: bsitikarn@gmail.com 
tourism destination, rich with grand heritage, inimitable history [5] and cultural diversity of over 30 ethnic minorities [6].

According to Chiang Rai Ethnic Networks, ethnics minorities in Chiang Rai are comprised of 17 linguistic distinctive groups of Tai Lue, Tai Yuan, Tai Yong, Tai Yai, Tai Kuen, Lua, Lisu, Bisu, Hmong, Lahu, Akha, Iu Mien, Karen (Pgazkoenyau), Khmu, Daraang, and the ethnic minorities in Mae Salong Area, with a population of over 100,000. (There are 52 Ethnic groups in Thailand). Their main religions are Buddhism, Animism and Christianity.

In general, the majority of ethnic's communities are scattered in the high land area. Due to historical and environmental contexts, they are quite isolated and have inhabited in the rural area. Thus, the ethnic minorities have a distinctive way of life, cultural exoticism surrounded with natural resources that are attractive for both domestic and foreign tourist [7]. Recently, majority of the ethnic minority in Chiang Rai are facing problems of poverty, natural resources deterioration and lacking of access to public health care and basic education with no identification as Thai citizen.

Therefore many of them turn to involved with illegal businesses such as drugs and human trafficking. These problems are seen as a threat to public security. Thus, a creative form of ethnic tourism has become a focal interest among the Internal Security Operation Command, Chiang Rai Ethnic Networks and tourism stakeholders as it has been recognized as a solution to the problems and a path to sustainability. However, the case remains to be made what form of ethnic tourism and what kind of operation shall be appropriated to the Chiang Rai-ethnic minorities' context.

Research objectives

To answer the above questions, this study aims to:

- explore the ethnic communities' demands on tourism development

- investigate the key players' roles and interests effecting on ethnic tourism promotion.

- identify key issues for an achievement of creative ethnic tourism promotion in Chiang Rai Province.

\section{Research Methodology}

To achieve the objectives of the study, the qualitative approach was employed in addition to the secondary data collection. These include street survey, in-depth interview the representatives of community leaders, participatory/non participatory observation, focus group discussion and Participatory Rural Appraisal (PRA) were employed in meeting with the ethnic villagers in different groups to explore their perceptions and demands on ethnic tourism promotion. The purposive sampling was applied to tourism stakeholders' population. The content analyses and descriptive analyses were employed to explain data.

\section{Results and Discussions}

\subsection{The Ethnic Communities' Demands on Tourism Development}

Since tourism has not yet taken place in the communities, the general views of ethnic communities indicate that tourism is perceived as a possible tool for employment and income generation.

They perceive that when their village becomes an attraction, there will be many visitors like many of other attractions. The main focus is now on economic issue, which has been evident in the ethnic villagers' interviews: 
'...We have big problem with poverty. So we wish that our village will become a tourist destination so... we can earn money from tourism. We heard that tourism is a good thing that can generate good income for us...'

'If we become a tourist destination, we can have income from performing culture shows for tourists and sell souvenirs of our handicrafts.'

Moreover, as majority of ethnic villagers are considered as non-Thai citizen, they don't haveID card. As a consequence, they are not able to travel out off the village to get any employment. At the same time, they do not have any access to public health care and any higher educationlevel. They believe that when tourism takes place in their village, the condition of life will be improved as they are seen and understood by tourist and their voice will be heard, which has been evident in the ethnic villagers' interviews

'... we need to be recognized by the authorities that we are exist. We are human. We need basic education and health care and better quality of life...but we are instead a scapegoat of being drug dealers and causes of natural resources deterioration... as we cannot get out...we want tourist to visit our home so they will understand us...the world outside will know us.'

In case of ethnic villagers who got an ID card, they immigrate from home town to attend higher education level and employment in big cities like Chiang Mai province and Bangkok. Some of them are business entrepreneurs for example, initiating tourist business by selling both items they had and what they bought from lowland markets including beautiful costumes, artifacts, farm products and etc.

Table 1. Ethnic Communities' Demands on Human Resource Development.

\begin{tabular}{|c|c|c|c|}
\hline \multirow{2}{*}{ Human Resource Development } & \multicolumn{3}{|c|}{$\begin{array}{c}\text { Demands on Tourism } \\
(\mathrm{n}=\mathbf{8 0})\end{array}$} \\
\hline & $\begin{array}{c}\text { YES } \\
\%\end{array}$ & $\begin{array}{c}\text { Uncertain } \\
\%\end{array}$ & $\begin{array}{c}\text { NO } \\
\%\end{array}$ \\
\hline $\begin{array}{c}\text { Sustainable tourism management and it } \\
\text { operation }\end{array}$ & 96 & 1 & 3 \\
\hline Tourism business and services & 86 & 3 & 11 \\
\hline $\begin{array}{c}\text { Tourism products and activities } \\
\text { development }\end{array}$ & 82 & 0 & 18 \\
\hline Home-stay business & 80 & 8 & 12 \\
\hline ICT Marketing & 78 & 0 & 22 \\
\hline Local -tourist guide & 77 & 8 & 15 \\
\hline Program tour-Costing & 72 & 0 & 28 \\
\hline Food and beverage hygiene & 71 & 3 & 26 \\
\hline English languages & 70 & 8 & 22 \\
\hline Thai languages & 48 & 16 & 36 \\
\hline
\end{tabular}

However, the majority of ethnic villagers recognized their weaknesses on tourism issues as they don't have any knowledge and skills on tourism management and its operation [8]. Many of them cannot even speak Thai and other languages. Therefore one of their wishes in tourism issues is the human resource development in aspects of tourism operation and related issues as identified in the following Table 1.

Data from Table 1 indicated that majority of ethnic villagers are keen on developing their knowledge and skills on sustainable tourism operation and related business and services, tourism products development, marketing and English language. However, to be success in ethnic tourism development, they also require help and supports from other tourism stakeholders such as government, travel agency and academic from educational institutions. 


\subsection{Key Players in Ethnic Tourism}

Due to the ethnic communities in Chiang Rai province context, the Internal Security Operation Command and the Border Patrol Police are main key players in ethnic tourism development. They have sought to suppress opium production and other kind of drugs and illegal matters in addition to control the communities and its members' to be within restricted area.

The Royal Project also promotes cash crops as replacement for opium cultivation in ethnic communities and has added tourism to its business since early 2000s (Royal Project 2003). In addition to the Chiang Rai Ethnic Networks, another prominent agency, in which intend to be a primary source of information for tourists, presenting art and artifacts of the ethnic groups as well as the locals' voice and needs to the authorities, public sectors including Ministry of Tourism and Sports, Tourism Authority of Thailand (TAT), and Tambon Authority Organization (TAO) see tourism as a solution to the problems of poverty and a tool for community development and a path to economic sustainability. They have significant interests and roles in ethnic tourism promotion.

Since ethnic tourism involve cultural exoticism and authentic souvenirs of ethnic groups, which are the key attractions, both the government and private sectors played a prominent role on taking the primitive images of ethnic groups through various kinds of mediato attract foreign tourists. It is essential in terms of marketing.

\subsection{Key Issues for an Achievement of Creative Ethnic Tourism Promotion}

Based on the ethnic community context and their demands on tourism promotion, this paper purposes key issues for an achievement of creative ethnic tourism promotion in Chiang Rai Province as shown in Figure 1 below.

From Figure 1, within the tensions of state regulation, modernity, cultural commodification, public security, resource deterioration, drug and poor access to basic health care and education, ethnic tourism $\{10,11]$ in Chiang Rai province may vary and differ among ethnic groups where their geography context is significant influence on ethnic tourism management and its operation.

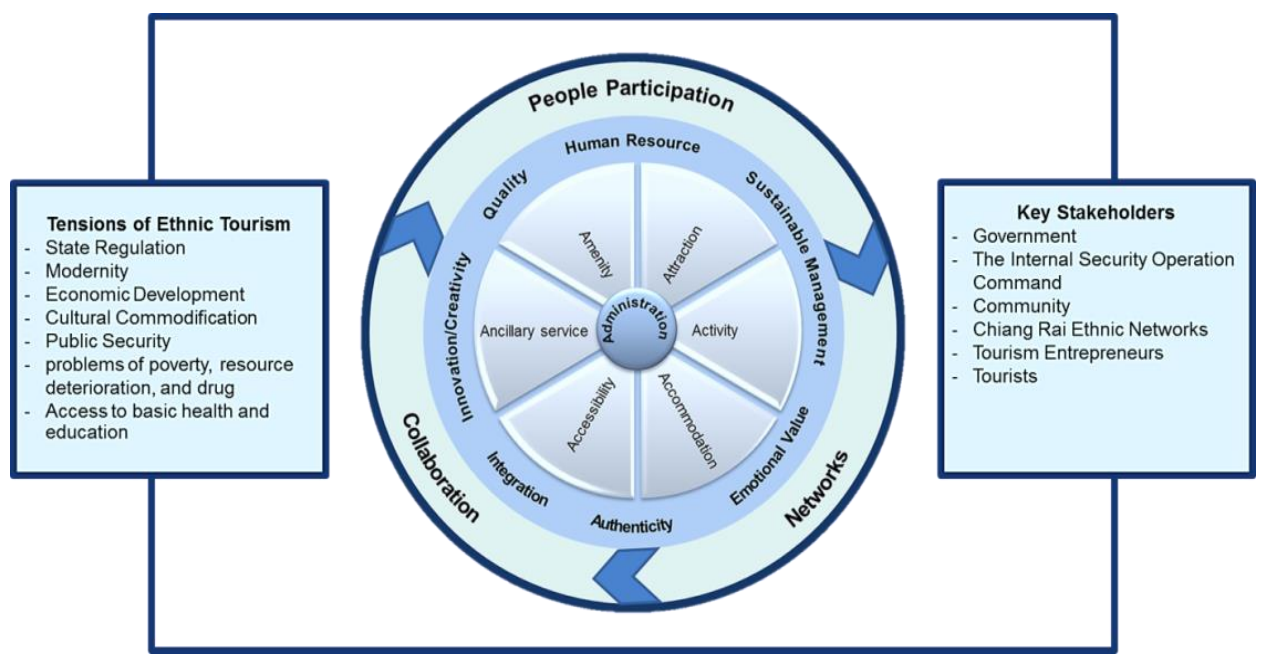

Fig. 1. Keys Success for Creative Ethnic Tourism in Chiang Rai Province [9].

However, to achieve sustainability, tourism management shall focus on providing visitors experiences of authenticity of locals' socio-culture as well as maximizing visitor 
experiences with satisfaction and emotional account.These can be done for example, through sensory experiences including sight, hearing, taste, touch and smell.Thus, in addition to maximize the quality of tourism products and services, integration and creativity play important roles in terms of operation that require involvement of the locals, supporting from other stakeholders and collaboration among them.

\section{Conclusion}

This study was intended to investigate the context of ethnic communities and explored their demands on ethnic tourism development and identified keys issues for an achievement of creative ethnic tourism promotion in context of Chiang Rai province.

The issues tackled in this study may not be new in other destination or other countries but it is so in terms of Chiang Rai province. The study recognized the limitation of how to apply those issues [12] in practice as the ethnic villagers who are main key player to operate ethnic tourism do not have knowledge and experiences in the issues. Although, human resource development is the priority of the development process, it may take ages to become a success. Therefore, supporting from other key stakeholders is essential.

\section{References}

1. M.M. Ihnatenko et al., International J. of Economics and Business Administration 7(2), 290-301 (2019)

2. I. Kayoko, Annals of Tourism Research 39(1), 290-310 (2012)

3. H. Kiyoshi, Ethnic Tourism and Cultural Change in the Border Region of Yunan province: A Case Study on Xishuangbanna (2014) http://coe.asafas.kyoto-u.ac.jp

4. D. Ushakov et al., Geojournal of Tourism and Geosites 27(4), 1429-1438 (2019)

5. A. Sanyal (2009) http://anandasanyal.blogspot.com/2009/06/ethnic-tourism-is-travelmotivated-by.html

6. E. Andreeva et al. Actual Problems of Economics 183(9), 220-227 (2016)

7. H.T. Van et al., Journal of International Studies 10(4), 109-118 (2017)

8. D. Ushakov et al., Journal of Environmental Management and Tourism 11(6), 13161327 (2020).

9. L. Yang et al., Tourism Management 30(4), 559-570 (2009)

10. O.V. Zakharchenko, Journal of Reviews on Global Economics 8, 859-872 (2019)

11. O.V. Takhumova et al., Journal of Applied Economic Sciences 13(7), 1939-1944 (2018)

12. D. Ushakov et al., Journal of Environmental Management and Tourism 11(4), 844-586 (2020) 